\title{
Potentiality of Bioconverted Leafy Vegetable Waste as Aquaculture Feed Supplement
}

\author{
Sujjat Al Azad*, Mohammad Tamrin Bin Mohamad Lal \\ Borneo Marine Research Institute, Universiti Malaysia Sabah, Sabah, Malaysia \\ Email: ^sujjat@ums.edu.my
}

How to cite this paper: Al Azad, S. and Lal, M.T.B.M. (2018) Potentiality of Bioconverted Leafy Vegetable Waste as Aquaculture Feed Supplement. Advances in Bioscience and Biotechnology, 9, 571-583. https://doi.org/10.4236/abb.2018.911040

Received: October 19, 2018

Accepted: November 19, 2018

Published: November 22, 2018

Copyright $\odot 2018$ by authors and Scientific Research Publishing Inc. This work is licensed under the Creative Commons Attribution International License (CC BY 4.0).

http://creativecommons.org/licenses/by/4.0/

\begin{abstract}
Purple non-sulfur bacteria (PNSB) are well known for their ability in transforming organic substrates for their own source of nutrients. The nutritional values of leafy vegetable waste could be improved through bioconversion with PNSB. This study was conducted to access nutritional status of leafy vegetable waste bio-converted product and efficacy of derived product as aquaculture feed supplement. Proximate compositions of bio-converted leafy vegetable wastes were improved after 6 days with 30\% inoculums of Afifella marina strain ME (KC205142). The crude proteins (\%) and ashes (\%) in derived product was increased to $51.7 \%$ and $19.6 \%$ respectively. On the other hand, the fiber (\%) in the bio-converted derived product was decreased by $21 \%$. During feeding trial in Tilapia (Oreochromis niloticus), no significant differences were observed in the feed intake ( $\mathrm{g} /$ fish/day), but significant differences were observed in the value of feed conversion ratio and weight gain (\%) among the used diets. However, lower ingestion rate $(\mathrm{g} / \mathrm{d} /$ fish $)$ and better feed conversion ratio were obtained while fishes were fed with diet composed of commercial feed mixed with $5 \%$ of the bio-converted product. The higher ingestion rate $(\mathrm{g} / \mathrm{d} / \mathrm{fish})$ and lower feed conversion ratio were observed with only commercial diet. There observed no significant differences in the ingestion rate $(\mathrm{g} / \mathrm{d} / \mathrm{fish})$ and $\mathrm{FCR}$ values among the diet composed of commercial feed with 5\% (D5) and 10\% (D10) of the bio-converted product. The derived bio-converted product can be a promising approach to open new market segment in aquafeed industry.
\end{abstract}

\section{Keywords}

Afifella marine, Vegetable Waste Powder, Bioconversion and Aquaculture Feed

\section{Introduction}

Most of the solid waste including fruits and vegetable wastes are directly disposed 
in municipal landfill or dumping sites causing environmental problems such as unpleasant smell [1]. The vegetable waste contains high calorific value with rich in nutritive values and supportive substrate for microbial biomass production [2]. It contains mainly starch, cellulose, soluble sugars and organic acids, which are utilized by some microorganisms for cellular activities and for the production of single-cell protein [3]. Purple non-sulfur bacteria (PNSB) are widely used in wastewater treatment [4]; it is suggested that they are capable of producing certain commercially importance by-products through the utilization of carbon source from the vegetable waste. PNSB, Rhodopseudomonas palustris and Rhodovulum sulfidophilum were proven ability in the utilization of food waste and effectively in digesting organic matter [5] [6].

The possibilities for increase in the protein values in vegetable waste in production of ammonia, amines, amino acids and peptides are due to autolysis during the process of bacterial fermentation. As good sources of crude protein, low neutral detergent fiber (NDF) and lignin contents in vegetable waste, they are suitable for animal feeding after certain treatments and processes [7]. Huge amount of vegetable wastes and valuable substances can be reduced and recycled through the fermentation or bioprocess for the production of value-added products. The improvement of nutritional value of by-product especially crude protein can be used as feeding additive and diet of cultured animal to reduce the cost and provide some nutritional contents for the animal. Higher nutritive values, like quality and quantity of protein, fibres and minerals are necessary to consider as alternate raw materials in replacement of expensive fish meal in feed industry.

The utilization of vegetable waste using bacteria especially purple non-sulfur bacteria to produced bacterial biomass for aquafeed might be potential option for researchers. However, there is little information available in the bioprocess of leafy vegetable waste and potentiality to be used as aquaculture feed supplement. This study was undertaken to evaluate the efficacy of co-fermented leafy vegetable waste as feed supplement in aqua feed. Locally isolated bacterium Afifella marina stain ME (KC205142) was used in bioprocess of leafy vegetable waste, as substrate to derived bacterial biomass.

\section{Materials and Methods}

\subsection{Collection of Leafy Vegetable Waste (LVW)}

Leafy vegetable waste (LVW) was collected from Likas vegetable market at Kota Kinabalu, Sabah. Only discarded or thrown LVW was collected from the area. The collected LVW was immediately transported to Borneo Marine Research Institute (BMRI) Biotechnology Laboratory for further process. The leafy vegetable waste was washed with tap water in the laboratory, chopped into smaller pieces and homogenized in blender. The homogenized vegetable waste was filtered through cheesecloth. The remaining solid portion as vegetable waste powder (VWP) was used in bioconversion process after dried in the oven at $65^{\circ} \mathrm{C}$ for $48 \mathrm{~h}$ and grinded into fine powder (smaller than $400 \mathrm{~mm}$ ). 


\subsection{Preparation of Inoculums}

Purple non-sulfur bacterium, Afifella marina stain ME (KC205142) was used in experiment in bioconversion process. The strain was taken from BMRI culture collection, which was isolated from mud of intertidal zone of mangrove in Kingfisher Park, Sabah, Malaysia [8]. The bacterium was incubated in 112 synthetic media for inoculums preparation. Synthetic 112 media is specific media used for the better growth of purple non-sulfur bacteria. The composition of 112 synthetic media was yeast extract $(10 \mathrm{~g})$, di-potassium hydrogen phosphate $(1 \mathrm{~g})$ and magnesium sulfate $(0.5 \mathrm{~g})$. All the ingredients of 112 synthetic media were mixed well in one liter distilled water and $29 \mathrm{ml}$ was dispensed into several $30 \mathrm{ml}$ universal bottles. The bottles were autoclaved at $121^{\circ} \mathrm{C}$ for 15 minutes for inoculums preparation. From the stock culture one $\mathrm{mL}$ of the culture was dispensed in $29 \mathrm{~mL}$ of previously autoclaved universal bottle and incubated anaerobically under 2500 lux of light intensity, at $30^{\circ} \mathrm{C} \pm 2^{\circ} \mathrm{C}$ for 48 -h. Subsequently inoculum was developed in $1 \mathrm{~L}$ Schott bottle.

\subsection{Bioprocess of Vegetable Waste Powder}

$20 \mathrm{~g}$ of previously dried vegetable waste powder (VWP) was mixed in $800 \mathrm{ml}$ of 112 synthetic media in one liter Schott bottle. Afifella marina inoculums of $30 \%$ $(\mathrm{v} / \mathrm{v})$ from 48 -h culture were inoculated into each Schott bottle. The bottles were incubated anaerobically under 2500 lux of light intensity, at $30^{\circ} \mathrm{C} \pm 2{ }^{\circ} \mathrm{C}$ for the period of 6 days. The product derived from the bioprocess of LVW was collected after six day and centrifuged at $4000 \mathrm{rpm}$ for 30 minutes. The obtained biomass was dried to a constant moisture level in oven at $60^{\circ} \mathrm{C} \pm 1^{\circ} \mathrm{C}$. The powder biomass was packed in air tight seal plastic bag and kept at $-4^{\circ} \mathrm{C}$ until used.

\subsection{Feeding Trial in Tilapia (Oreochromis niloticus) Using Bioprocess VWP Derived Product}

\section{Diet Preparation}

Three diets were used in feeding trial. Diet with $5 \%$ bio-converted product mixed with commercial diet (D5), Diet with $10 \%$ bio-converted product mixed with commercial diet (D10) and commercial diet (D0) used as control. The commercial tilapia pellet was grinded into powder form and mixed with derived bioprocess VWP at 5\% (D5) and 10\% inclusion level (D10). After proper mixing diet was re-pelleting and dried in oven at $60^{\circ} \mathrm{C}$ for complete dryness

\subsection{Trial Species}

Feed were fed to triplicate group of 20 (mean weight $1.0 \pm 0.1 \mathrm{~g}$ ) juveniles (Oreochromis niloticus) cultured in $150 \mathrm{~L}$ tank. Body weight gained (\%), feed intake ( $\mathrm{g} /$ fish/day), feed conversion ratio and survival (\%) were evaluated after 30 days of feeding trial.

\subsection{Feeding Management}

The experimental fish was fed two times in a day ( 7 am and $4 \mathrm{pm})$. The juveniles 
were fed up to satiation level and during feeding time the behaviour of Oreochromis niloticus also observed. Weighed quality of feed were used and recorded for the analysis of feed conversion ratio and feed intake within 30 days feeding trial. Bottom cleaning was done every day to remove excess waste and fecal materials from the tank after late feeding.

\section{Analytical Parameters}

\subsection{Proximate Composition Analysis of Vegetable Waste Powder (VWP)}

The proximate composition analyses were carried out to identify the differences of the nutritional value of the bioprocess product. Estimation of crude protein was done using KjeltecTM 2300 Auto-analyzer Unit, crude fiber after hydrolysis with strong acid and alkali using Fibertec ${ }^{\mathrm{TM}} 1020$ and crude fat extracted in petroleum ether using SoxtecTM System 2043 Extraction Unit of Foss Tecator, Sweden, and crude ash (\%) was determined using muffle furnace. This estimation was conducted according to the standard methods of AOAC [9].

\subsection{Feeding Trial}

Every day water quality such as dissolved oxygen concentration (mg/L), $\mathrm{pH}$ and temperature $\left({ }^{\circ} \mathrm{C}\right)$ from each tank was measured by using HANNA Multi-parameter. The proximate composition of the experimental diets such as moisture, crude protein, crude lipid crude fiber and ash were analysed according to the standard methods of AOAC [9].

Nitrogen Free Extract (NFE) was computed according to following formula:

$$
\mathrm{NFE}(\%)=\% \mathrm{DM}-(\% \mathrm{CP}+\% \mathrm{CL}+\% \mathrm{CF}+\% \mathrm{Ash})
$$

where: $\mathrm{NFE}=$ nitrogen free extract, $\mathrm{DM}=$ dry matter, $\mathrm{CP}=$ crude protein, $\mathrm{CL}=$ crude lipid and $\mathrm{CF}=$ crude fiber.

The growth performance parameter in juveniles Oreochromis niloticus such as Total feed intake ( $\mathrm{g} / \mathrm{fish}$ ), feed conversion ratio (FCR), ingestion rate (g/d/fish), weight gain (\%) and survival (\%) were calculated according to the formula described by [10].

\subsection{Statistical Analysis}

One way ANOVA was used to determine significance difference (5\% level) between the growth performances of juveniles Oreochromis niloticus fed with three diets using SPSS version 10 and Micorsoft excel.

\section{Results}

\subsection{The Effects of Afifella marina Strain ME (KC205442) on the Change of Proximate Composition of Vegetable Waste Powder (VWP)}

At the end of $6^{\text {th }}$ day the proximate compositions of the bioprocess VWP were 
observed to improve with the increment of the protein and ash, and with the reduction of the crude fiber value. The value in crude protein was increased to $51.7 \%$ at day 6 while the value in ash was also observed to increase $19.6 \%$. On the other hand the value in crude fiber was observed to decrease $21 \%$ in bioprocess VWP (Table 1). The increase in protein value and decrease in fiber have advantages in processed VWP to be uses as feed ingredient.

\subsection{Feeding Trial}

The proximate compositions of the diets used in this experiment determined different as diets were not formulated based on the dietary protein level. Diets were prepared with the addition of $5 \%$ and $10 \%$ bioprocess VWP.

The diet supplemented with process VWP found to contained higher amount of protein. The highest protein of $42.02 \%$ and subsequently $36.57 \%$ of protein were observed in D5 and D10 respectively (Table 2).

The mean values of the dissolved oxygen, $\mathrm{pH}$ and temperature were observed within the optimum levels foe the culture of Tilapia in tank system (Table 3).

During feeding trial no significant differences were observed in feed intake ( $\mathrm{g} /$ fish/day) and survival (\%) among the used diets. However lower ingestion rate and best feed conversion ratio were obtained while fishes were fed with diet D5

Table 1. Summary of the proximate compositions of leafy vegetable waste before bioprocess and after bioprocess with Afifella marina strain ME (KC205442).

\begin{tabular}{cccccccccccc}
\hline \multirow{2}{*}{ A. marina } & \multicolumn{2}{c}{$\begin{array}{c}\text { Crude } \\
\text { protein (\%) }\end{array}$} & \multicolumn{2}{c}{$\begin{array}{c}\text { Crude } \\
\text { lipid (\%) }\end{array}$} & \multicolumn{2}{c}{$\begin{array}{c}\text { Crude } \\
\text { fiber (\%) }\end{array}$} & \multicolumn{2}{c}{ Ash (\%) } & \multicolumn{2}{c}{ NFE (\%) } \\
\cline { 2 - 11 } & Day 0 & Day 6 & Day 0 & Day 6 & Day 0 & Day 6 & Day 0 & Day 6 & Day 0 & Day 6 \\
\hline Control & 14.5 & 14.7 & 1.5 & 1.6 & 15.3 & 11.5 & 23.0 & 24.8 & 45.7 & 47.4 \\
$30 \%$ & 14.9 & 22.6 & 1.5 & 1.8 & 16.0 & 12.6 & 23.0 & 27.5 & 44.6 & 35.5 \\
\hline
\end{tabular}

Table 2. Proximate composition of three diets prepared with the supplementation of $5 \%$ (D5), 10\% (D10) VWP and without supplementation of VWP (D0). The values are express as mean \pm std dev.

\begin{tabular}{cccccc}
\hline \multicolumn{5}{c}{ Proximate Composition (\%) } \\
\hline Diets & Moisture & Ash & Lipid & Fibre & Protein \\
\hline D0 & $3.96 \pm 0.12$ & $12.56 \pm 0.08$ & $9.00 \pm 2.20$ & $6.03 \pm 0.05$ & $32.92 \pm 0.44$ \\
D5 & $6.81 \pm 0.04$ & $13.32 \pm 0.08$ & $8.31 \pm 0.65$ & $4.25 \pm 0.64$ & $36.57 \pm 0.85$ \\
D10 & $3.99 \pm 0.02$ & $13.55 \pm 0.04$ & $9.25 \pm 3.08$ & $3.91 \pm 0.50$ & $42.02 \pm 0.37$ \\
\hline
\end{tabular}

Table 3. The values of water quality parameters measured in the tank of juveniles (Oreochromis niloticus) during feeding trial (average \pm std dev).

\begin{tabular}{cc}
\hline Parameters & Obtained values \\
\hline Dissolved oxygen (DO) & $6.33 \pm 0.92 \mathrm{mg} / \mathrm{L}$ \\
$\mathrm{pH}$ & $7.20 \pm 0.51$ \\
Temperature & $30.22^{\circ} \mathrm{C} \pm 0.38^{\circ} \mathrm{C}$ \\
\hline
\end{tabular}


(commercial feed and 5\% of the bio-converted product). The higher ingestion rate and lower feed conversion ratio were observed with diet D0 (only commercial feed) and D10 diet (commercial feed and 10\% of the bio-converted product) respectively. There observed significantly differences in the feed conversion ratio (FCR), ingestion rate and weight gain of tilapia juveniles when fed with control diet (D0) and supplement diets (D5 and D10), but no significant differences were observed among the diets D5 and D10 (Table 4).

\section{Discussion}

\section{The Effects of Afifella Marina on the Change of Proximate Composition in Vegetable Waste Powder (VWP)}

Biotransformation characteristics of purple non-sulfur bacteria are relatively well known due to their inhabitant [11]. Purple non sulfur bacteria are well known with their characteristic of organic transformation [12]. The purple non-sulfur bacteria, Afifella marina was expected to be able in increasing the nutritional value of vegetable waste; in term of dry biomass basis including crude protein, crude lipid and crude ash; under standard liquid state fermentation with light intensity of 2500 lux at $30^{\circ} \mathrm{C} \pm 2^{\circ} \mathrm{C}$ temperature. The products of fermentation in Afifella marina inoculated and without inoculated substrates, were investigated for proximate composition changes in 112 synthetic media added with 20 $\mathrm{g}$ of vegetable waste powder.

Under the presence of Afifella marina, the maximum crude protein of vegetable waste biomass recorded on day 6 increased to $22.6 \%$ from initial value. The increment of crude protein observed under the presence of bacteria might be due to the increasing of biomass of Afifella marina [13]. The inoculated bacteria might convert some vegetable protein or other nitrogenous compounds available in the environment into cell protein for microbial mass production [14]. The increasing in microbial mass during fermentation course causes extensive hydrolysis of protein molecules available in vegetable waste powder into amino acid and other simple peptides for absorption [15]. Strain of purple non-sulfur bacterium Rhodopseudomonas palustris efficiently cultured in wastewater under anaerobic condition for the production of single cell protein [16]. In present study the strain of Afifella marina strain ME (KC205442) might be a potential

Table 4. Growth performances of Oreochromis niloticus juveniles fed with three different types of diets.

\begin{tabular}{cccc}
\hline Parameters & D0 & D1 & D2 \\
\hline Total feed intake (g/fish) & $14.93 \pm 0.78^{\mathrm{a}}$ & $15.26 \pm 0.75^{\mathrm{a}}$ & $15.42 \pm 0.76^{\mathrm{a}}$ \\
Feed conversion ratio (FCR) & $1.95 \pm 0.39^{\mathrm{a}}$ & $1.43 \pm 0.18^{\mathrm{b}}$ & $1.49 \pm 0.30^{\mathrm{b}}$ \\
Ingestion rate (g/d/fish) & $1.21 \pm 1.43^{\mathrm{a}}$ & $0.53 \pm 0.44^{\mathrm{b}}$ & $0.65 \pm 0.23^{\mathrm{b}}$ \\
Weight gain (\%) & $269.50 \pm 4.58^{\mathrm{a}}$ & $287.92 \pm 8.95^{\mathrm{b}}$ & $291.04 \pm 5.92^{\mathrm{b}}$ \\
Survival (\%) & 100 & 100 & 100 \\
\hline
\end{tabular}

Values with different superscripts differ significantly $(\mathrm{p}>0.05)$. 
PNSB species in producing single cell protein (SCP) and thus increase in protein during bioprocess. The enzymes such as protease, lipases, esterase and alkaline phosphate have reported to be produced by PNSB [17]. PNSB, Afifella marina might utilize the organic matters in vegetable waste powder for the secretion of proteolytic enzymes [18]. The proteolytic enzyme secreted plays an important role in providing nutrients and altering extracellular polymeric substances composition, which might help the growth of the bacteria [18]. The increment of crude protein value of $22.6 \%$ in current study is comparatively lower with the value of $30.12 \%$ and $37.63 \%$ using yeast, Aspergillus niger with different strains [14]. However, the optimum fermented period for crude protein production is day 6 in current study was shorter than the study of Rajesh and others [14], which suggested best harvesting on day 8 and day 7 for maximum crude protein production.

The crude lipid of bioprocess product was observed little increase during the course of process. The pattern of crude lipid using yeast, Aspergillus niger, on vegetable waste showed decreasing followed by an increasing trend [14], whereas current study showed an opposite pattern. The lower increased of crude lipid value in present study can be explained by assimilation of lipids from the vegetable waste powder for bacteria biomass production during the course of bioprocess [19]. The free fatty acid in the substrates might be converted for the formation of cell membrane during the growth of bacteria. The increment of crude lipid value might be due to the breaking down of large unused fat molecule from the vegetable waste to simpler fatty acid units using lipolytic enzyme [15]. This enzyme shows a behavior called interfacial activation, which increasing in substrate concentrations can stimulate the lipolytic activity of the enzymes causing the breaking down of large fat molecules [20].

Breakdown of fiber composition in the VWP in this study during bioprocess is direct involvement of bacterium in the increased of value of protein. The subsequent substances are to be used by the bacteria as a carbon source to synthesis bacterial biomass rich in protein. The breakdown of fiber and bioconversion into protein may also due to secretion of enzymes, which are proteinous in nature, during bioprocess. Afifella marina strain ME (KC205442) is capable to produce proteolytic enzymes, which produces protease under anaerobic light conditions at temperature of $30^{\circ} \mathrm{C} \pm 2^{\circ} \mathrm{C}$. The optimum proteolytic activity was recorded at $48 \mathrm{~h}$ of incubation, which also explains the high level of crude protein at Day 2 and Day 4 in this study [18]. In addition, the extracellular proteases within the bacterium extracellular polymeric substances matrix play an important role in providing nutrients and alter extracellular polymeric substances composition [18]. The proteolytic activity of Afifella marina strain ME (KC205442) increases with dry cell weight, which the highest dry cell weight obtained was of $4.97 \mathrm{~g} / 1$ and proteolytic activity of $74.7 \pm 2.31 \mathrm{U}$. It indicated that Afifella marina might secrete proteolytic enzyme to hydrolyze high molecular weight compound outside the cell, prior to the uptake of growth. Extracellular enzymes contributed to 
the nutrition of the bacterium by hydrolyzing large molecular organic compounds to smaller monomeric components which can readily absorbed by the bacterial cells [21]. In the fermentation vegetable discards (cabbage, cauliflower, banana peel, banana, potato, carrot, beet root, ladies finger, peas, beans, capsicum etc.) using $A$. niger NCIM 616 the values of fiber content was observed to decrease as fermentation proceeded. Initial fibre content was 9.82 and was finally reached at 8.26 at day 8 , which was around $15 \%$ increased in value. The value of fiber in VWP before bioprocess was observed 16.0 and finally reached to $12.6 \%$ at day $6^{\text {th }}$ indicated $21 \%$ reduction in crude fiber. They concluded that the reduction may be attributed to the breakdown of non-starch polysaccharide by the fungi to fungal protein.

The crude ash value of the process product recorded in the current study reached the value of $27.5 \%$ on day 6 in the presence of Afifella marina. However, overall the crude ash of VWP product was as the expectation, which increased after the bioprocess. The increasing of crude ash in VWP product in bacteria inoculated substrates might be due to the releasing of biological molecules such as enzyme can result in breaking down the organic components of vegetable waste into their absorbable form by the bacteria [15]. The loss of organic matter might increase the crude ash through the fermentation process [14]. The increment of crude ash in current study was relatively lower compare to the study of Rajsh and others 14]. The crude ash recorded in vegetable waste utilization using yeast, Aspergillus niger strain S14 and NCIM 616 increased 44.73\% and 29.05\% respectively, whereas the maximum crude ash increment recorded in current study was $14.88 \%$ on day 2 . The pattern of crude ash changes in current study was in disagreement with most of the study on crude ash changes during fermentation, which only increased after fermentation [22]. The unfermented samples were unlikely to have more mineral elements compared to the fermented products [22]. The possibility of microorganisms used minerals for their reproductive activities was low, however all living organisms require some mineral elements to maintain metabolic functions [23]. All living organisms required some mineral elements to maintain some metabolic functions but there was no appreciable decrease in the mineral composition of fermented agro-industrial residues [24]. Afifella marina strain ME (KC205442) might use the mineral elements in substrates for cellular activities or releasing biological macromolecules causing the slight decrement of crude ash after day 6, but need further investigation.

The percentage decrease in NFE from the initial value was $28 \%$ using $A$. niger S14, during the course of fermentation and 22\% using A. niger NCIM 616. Loss in NFE was observed in the fermented products in both the trials. Similar pattern was also observed when VWP uses in bioprocess to produce product. The value of NFE initially was observed $44.6 \%$ and $t$ day $6^{\text {th }}$ gradually observed to decrease at $35.5 \%$. Loss of NFE in palm kernelmeal during SSF due to its conversion into fungal protein biomass was reported [19]. In the present investigation since $A$. niger is more rapidly amylolytic, a great amount of carbohydrate might 
have been broken down during the course of fermentation. Purple non-sulfur bacteria have capability to utilized wide range of substrates and use diverse metabolic pathway to utilize all nitrogen and carbon substrate [25]. However little information is available on the amylolytic activity of Afifella marina strain ME (KC205442) and also need further investigation.

The bioprocess of VWP with microbe had modified the ingredient to easilydigestible components with the release of enzymes that remain in the product. Diets containing alternate plant protein sources are able to meet the nutritional requirement of aquaculture species and assumed better growth performance. In general, growth and feed utilization efficiencies of fish fed fermented Duckweed (Lemma polyrhiza) leaf meal containing diets were superior to those fed diets containing raw leaf meal [26]. Growth response, feed conversion ratio and protein efficiency ratio resulted better performance in Indian major carp, Labeorohita fingerlings while fed with $30 \%$ fermented grass pea seed meal incorporated diet. The growth performance and feed utilization efficiency in fish fed fermented plant meal incorporated diet, performed better than those fed unfermented diets [27]. In present study, preliminary feeding trial was conducted for 30 days in Red tilapia, Oreochromis niloticus juveniles with the bioprocess VWP product as a supplementation of commercial diet and commercial feed as a control diet. The growth performances of the Red tilapia Oreochromis niloticus juveniles have significant differences among the supplementation and commercial feed.

The higher feed intake and lower ingestion rate observed while fish fed with D5 together with best FCR value indicates the potentiality of the feed in aquaculture species. The protein level was determined higher with the supplementation of bioprocess VWP in feed resulted with the higher weight gain in Oreochromis niloticus juveniles, but no significant difference was observed while fed with D5 and D10. Protein content in Diet 10 observed higher than the Diet 5, but content of fiber in Diet 5 observed higher. The crude fiber assumed as indigestible organic fraction of the diets and included in feed within the range of $0.5 \%-8 \%$. However the reduction of the crude fibre content of fish diet essential criteria for nutritionally balanced diets. Tilapia is omnivorous have capability to utilize fibre and they need an indigestible proportion of their diet to support the digestion, but within the limit. So it can be concluded that protein is not only criteria to evaluate the feed quality, but other growth promoting co-factors play important roles in metabolism and thus contribute in feed quality. The presence of essential amino acids and fatty acids in feed staff together with vitamins and minerals in accurate proportion vitally necessary for quality feed. In general plant-based protein sources are usually low in tryptophan and methionine, which are the essential amino acids [27]. So, the acceptability of the diets was not the same, and this difference may have affected the feed intake and ultimately the growth of fish. Additive used during processing of feed usually increases the palatability of a diet. However, it was very hard to conclude about palatability from present study, as the essential amino acids and fatty acids in the bioprocess 
product from VPW not investigated.

During Bioprocess VWP with PNSB Afifella marina strain ME (KC205442) the bacterium not only involves in the improvement of proximate compositions, but the microbial biomass also contributed value added properties in the processed product. The nutritional value of purple non-sulfur bacteria (PNSB) bacteria clearly indicated that it could be used as a potential protein supplement. The survival rate of $96.5 \%$ carp when PSB was fed at $0.1 \%$ supplemented with commercial feed [4]. Further the biomass of PNSB could be used as aquaculture feed supplement [28] and also as feed additive in rearing shrimp larvae [29]. The self-flocculated bacterium Rhodovulum sp. is not only rich in high quality protein, but also contains significantly large amounts of carotenoid pigments, biological co-factor and vitamins that might enhance the growth and survival in fish [4]. The bacterium Afifella marina strain ME (KC205442) capable to produce significant amount of caratenoids and extracellular enzymes which might contributes as growth promoting factors when added in the fish feed. The production of total carotenoid of $0.78 \mathrm{mg} / \mathrm{g}$ dry cell weight was obtained in the cell of A. marina was when the bacterium exposed to a light intensity of $2.5 \mathrm{klx}$ and incubated for $48 \mathrm{~h}$ [8]. The use of beneficial bacterium Bacillus $\mathrm{sp}$ in improving growth and FCR are well documented [30]. Results from present study suggested that the D5 and D10 contained the Afifella marina bacterial cells which might enhance the digestive processes by providing various enzymes. These enzymes produced by the bacterium Afifella marina [18] help in extracting more nutrients from the feed and therefore improving feed utilization and assimilation with the improvement of FCR value [30]. However, present study just only conducted on preliminary basis. More comprehensive and detail studies should be conducted to evaluate the feed as complete diet not only for Oreochromis niloticus juveniles, but for other commercially important aquaculture species. Supplementation with EAA and EFA as well as other feed additive in the bioprocess VWP product are vitally important.

\section{Conclusion}

Purple non-sulfur bacterium, Afifella marina, plays a prominent role in improving the nutritional value of vegetable waste during in the bioprocess. The harvesting of bioprocess vegetable waste biomass depends on the components desired in term of the nutrients. This study was conducted in the prospect of $A f i$ fella marina being used to reduce the vegetable waste that has been the issue in term of environmental, health and ecological. Based on the current study, the ability of Afifella marina in vegetable waste utilization is promising. The advantages of using VWP bioprocess product as aquaculture feed is to utilize as supplement to increase growth performance in tilapia in addition to reduce environmental pollution due to the improper disposal of this non-conventional resources. The product might have potential as supplement or feed additive in the aquaculture species. 


\section{Acknowledgements}

This study was supported by the grant of SBK0307.2017 from University Malaysia Sabah, Kota Kinabalu, Sabah, Malaysia and authors also appreciated the support from staff of Borneo Marine Research Institute, University Malaysia Sabah, Kota Kinabalu, Sabah, Malaysia.

\section{Conflicts of Interest}

The authors declare no conflicts of interest regarding the publication of this paper.

\section{References}

[1] Sitorus, B., Sukandar and Panjaitan, S.D. (2013) Biogas Recovery from Anaerobis Digestion Process of Mixed Fruit-Vegetable Wastes. Energy Procedia, 32, 176-182. https://doi.org/10.1016/j.egypro.2013.05.023

[2] Prakash, E.V. and Singh, L.P. (2013) Biomethanation of Vegetable and Fruit Waste in Co-digestion Process. International Journal of Emerging Technology and Advanced Engineering, 3, 493-495.

[3] Stabnikova, O., Wang, J.-Y., Ding, H.B. and Tay, J.-H. (2005) Biotransformation of Vegetable and Fruit Processing Waste into Yeast Biomass Enriched with Selenium. Bioresource Technology, 96, 747-761. https://doi.org/10.1016/j.biortech.2004.06.022

[4] Kobayashi, M. and Kobayashi, M. (2001) Roles of Phototrophic Bacteria and Their Utilization. In: Kojima, H. and Lee, Y.K., Eds., Photosynthetic Microorganisms in Environmental Biotechnology, Springer-Verlag, Hong Kong, 11-26.

[5] Mekjinda, N. and Ritchie, R. (2015) Breakdown of Food Waste by Anaerobic Fermentation and Non-Oxygen Producing Photosynthesis Using a Photosynthetic Bacterium. Waste Management, 35, 199-206.

https://doi.org/10.1016/j.wasman.2014.10.018

[6] Azad, S., Vikineswary, S. and Chong, V. (2003) Rhodovulum sulfidophilum in the Treatment and Utilization of Sardine Processing Wastewater. Letters in Applied Microbiology, 38, 13-18. https://doi.org/10.1046/j.1472-765X.2003.01435.x

[7] Wadhwa, M., Kaushal, S. and Bakshi, M.P. (2006) Nutritive Evaluation of Vegetable Wastes as Complete Feed for Goat Bucks. Small Ruminant Research, 64, 279-284. https://doi.org/10.1016/j.smallrumres.2005.05.017

[8] Soon, T.K., Azad, S.A. and Ransangan, J. (2014) Isolation and Characterization of Purple Non-Sulfur Bacteria, Afifella marina, Producing Large Amount of Carotenoids from Mangrove Microhabitats. Journal of Microbiology and Biotechnology, 24, 1034-1043. https://doi.org/10.4014/jmb.1308.08072

[9] AOAC (2003) Official Methods of Analysis of the Association of Official's Analytical Chemists. AOAC, Arlington, Virginia.

[10] Steffens, W. (1989) Principles of Fish Nutrition. Ellis Horwood, Chichester.

[11] Madigan, M.T. and Jung, D.O. (2008) An Overview of Purple Bacteria: Systematics, Physiology and Habitats. In: Hunter, C.N., Ed., The Purple Phototrophic Bacteria, Springer, Netherlands.

[12] Azad, S.A., Jie, W.H. and Lal, M.T.B.M. (2018) Utilization of Vegetable Waste Juice by Purple Non-Sulfur Bacterium (Afifella marina Strain ME) for Biomass Production. Journal of Geoscience and Environment Protection, 6, 210-219. https://doi.org/10.4236/gep.2018.65017 
[13] Akintomide, M.J. and Antai, S.P. (2012) Protein Enrichment of Irish Potato (Solanium tuberosium) Peels through Solid Substrate Fermentation by Saccharomyces cerevisiae and Aspergillus niger. Journal of Environmental Science, 1, 15-19.

[14] Rajesh, N., Imelda-Joseph. and Paul Raj, R. (2010) Value Addition of Vegetable Wastes by Solid-State Fermentation Using Aspergillus niger for Use in Aquafeed Industry. Waste Management, 30, 2223-2227. https://doi.org/10.1016/j.wasman.2009.12.017

[15] Igbabul, B.D., Amove, J. and Twadue, I. (2014) Effect of Fermentation on the Proximate Composition, Antinutritional Factors and Functional Properties of Cocoyam (Colocasia esculenta) Flour. African Journal of Food Science and Technology, 5, 67-74.

[16] Honda, R., Fukushi, K. and Yamamoto, K. (2006) Optimization of Wastewater Feeding for Single-Cell Protein Production in an Anaerobic Wastewater Treatment Process Utilizing Purple Non-Sulfur Bacteria in Mixed Culture Condition. Journal of Biotechnology, 125, 565-573. https://doi.org/10.1016/j.jbiotec.2006.03.022

[17] Tielen, P., Rosenau, F., Wilhelm, S., Jaeger, K., Flemming, H. and Wingender, J. (2010) Extracellular Enzymes Affect Biofilm Formation of Mucoid Pseudomonas aeruginosa. Microbiology, 156, 2239-2252. https://doi.org/10.1099/mic.0.037036-0

[18] Azad, S., Tan, K. and Ransangan, J. (2013) Effects of Light Intensities and Photoperiods on Growth and Proteolytic Activity in Purple Non-Sulfur Marine Bacterium, Afifella marina Strain ME (KC205142). Advances in Bioscience and Biotechnology, 4, 919-924. https://doi.org/10.4236/abb.2013.410120

[19] Wing Keong, N.G., Lim, H.A., Lim, S. and Ibrahim, C.O. (2002) Nutritive Value of Palm Kernel Meal Pretreated with Enzyme or Fermented with Trichoderma koningii (Oudemans) as a Dietary Ingredient for Red Hybrid Tilapia (Oreochromis sp.). Aquaculture Research, 33, 1199-1207. https://doi.org/10.1046/j.1365-2109.2002.00757.x

[20] Brockerhoff, H. and Jensen, R. (1974) Lipolytic Enzymes. Academic Press, Inc., Mishawaka.

[21] Prakash, B., Veeregowda, B. and Krishnappa, G. (2003) Biofilms: A Survival Strategy of Bacteria. Current Science, 85, 1299-1307.

[22] Akinyele, B., Olaniyi, O. and Arotupin, D. (2011) Bioconversion of Selected Agricultural Wastes and Associated Enzymes by Volvariella volvacea: An Edible $\mathrm{Mu}$ shroom. Research Journal of Microbiology, 6, 63-70.

https://doi.org/10.3923/jm.2011.63.70

[23] Frazier, C. and Westhoff, C. (1978) Food Microbiology. McGraw Hill, Inc., New York.

[24] Bennet, J.W., Wunch, K.G. and Faison, B.D. (2002) Use of Fungi in Bioremediation. In: Hurst, J.C., Ed., Manual of Environmental Microbiology, 2nd Edition, ASM Press, Washington DC, 960-971.

[25] Sasaki, K., Noparatnaraporn, N. and Nagi, S. (1991) Use of Photosynthetic Bacteria on the Production of SCP and Chemicals from Agro-Industrial Wastes. In: Martin, A.M., Ed., Bio-Conversion of Waste Materials to Industrial Products, Elsevier Science Publishers BV, Amsterdam, 223-265.

[26] Bairagi, A., Ghosh, K.S., Sen, S.K. and Ray, A.K. (2002) Duckweed (Lemna polyrhiza) Leaf Meal as a Source of Feedstuff in Formulated Diets for Rohu (Labeorohita Ham.) Fingerlings after Fermentation with Fish Intestinal Bacterium. Bioresource Technology, 85, 17-24. https://doi.org/10.1016/S0960-8524(02)00067-6 
[27] Ramachandran, S., Bairagi, A. and Ray, A.K. (2005) Improvement of Nutritive Value of Grass Pea (Lathyrus sativus) Seed Meal in the Formulated Diets for Rohu, Labeo rohita (Hamilton) Fingerlings after Fermentation with a Fish Gut Bacterium. Bioresource Technology, 96, 1465-1472.

https://doi.org/10.1016/j.biortech.2004.12.002

[28] Banerjee, S., Azad, S., Vikineswary, S., Selvaraj, O.S. and Mukherjee, T.K. (2000) Phototrophic Bacteria as Fish Feed Supplement. Asian-Austalaian Journal of Animal Sciences, 13, 991-994. https://doi.org/10.5713/ajas.2000.991

[29] Azad, S.A., Chong, V.C. and Vikineswary, S. (2002) Phototrophic Bacteria as Feed Supplement on Rearing Penaeus monodon Larvae. Journal of the World Aquaculture Society, 33, 158-168. https://doi.org/10.1111/j.1749-7345.2002.tb00490.x

[30] Ridha, M.T. and Azad, I.S. (2012) Preliminary Evaluation of Growth Performance Andimmune Response of Nile Tilapia Oreochromis niloticus Supplemented with two Putative Probiotic Bacteria. Aquaculture Research, 43, 843-852.

https://doi.org/10.1111/j.1365-2109.2011.02899.x 